
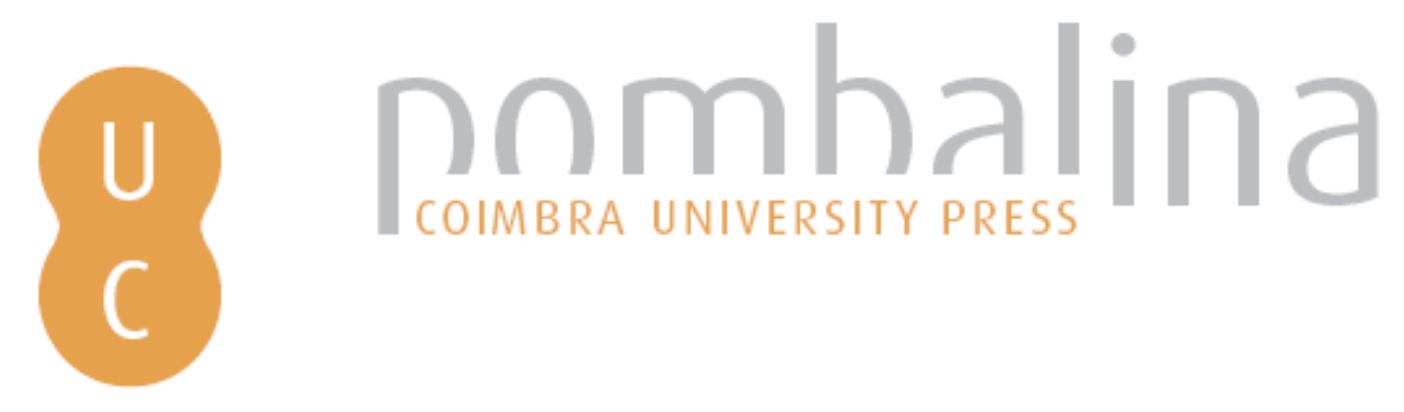

\title{
Analysis of fire spread across a two-dimensional ridge under wind conditions
}

Autor(es): $\quad$ Raposo, Jorge; Cabiddu, Salvatore; Viegas, Domingos X.; Salis, Michele; Sharples, Jason

Publicado por: Imprensa da Universidade de Coimbra

URL

persistente: URI:http://hdl.handle.net/10316.2/34026

DOI: $\quad$ DOI:http://dx.doi.org/10.14195/978-989-26-0884-6_7

Accessed : $\quad$ 26-Apr-2023 15:00:17

A navegação consulta e descarregamento dos títulos inseridos nas Bibliotecas Digitais UC Digitalis, UC Pombalina e UC Impactum, pressupõem a aceitação plena e sem reservas dos Termos e Condições de Uso destas Bibliotecas Digitais, disponíveis em https://digitalis.uc.pt/pt-pt/termos.

Conforme exposto nos referidos Termos e Condições de Uso, o descarregamento de títulos de acesso restrito requer uma licença válida de autorização devendo o utilizador aceder ao(s) documento(s) a partir de um endereço de IP da instituição detentora da supramencionada licença.

Ao utilizador é apenas permitido o descarregamento para uso pessoal, pelo que o emprego do(s) título(s) descarregado(s) para outro fim, designadamente comercial, carece de autorização do respetivo autor ou editor da obra.

Na medida em que todas as obras da UC Digitalis se encontram protegidas pelo Código do Direito de Autor e Direitos Conexos e demais legislação aplicável, toda a cópia, parcial ou total, deste documento, nos casos em que é legalmente admitida, deverá conter ou fazer-se acompanhar por este aviso.

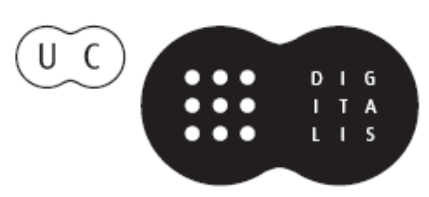




\section{ADVANCES IN}

Forest Fire

\section{RESEARCH}

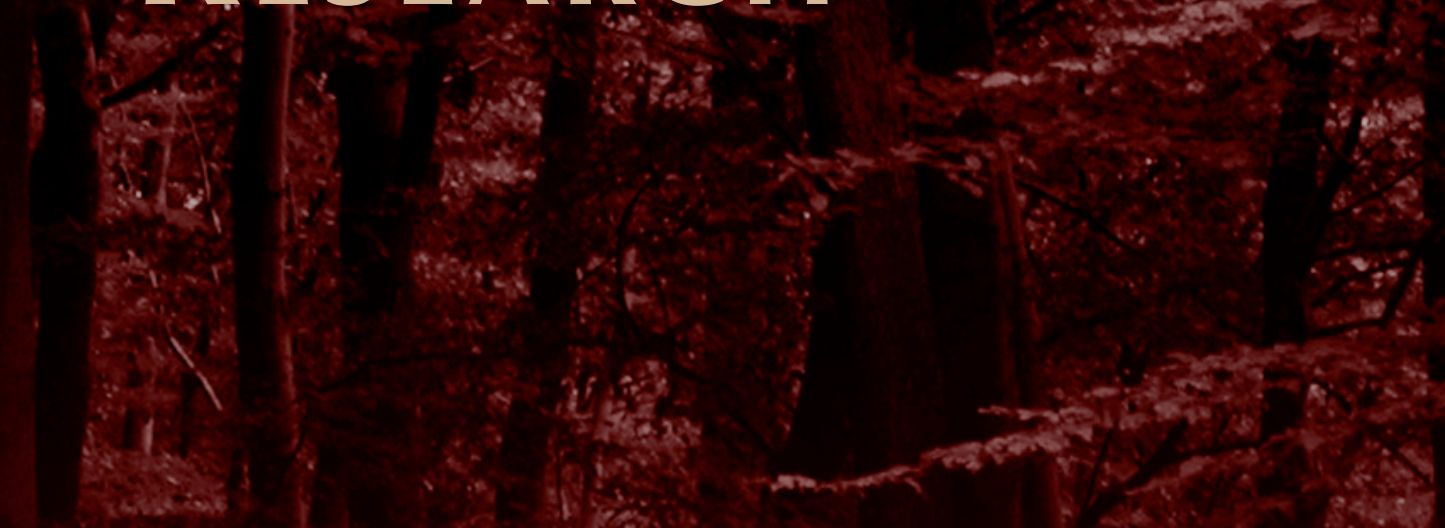

\section{DOMINGOS XAVIER VIEGAS}

\section{EDITOR}




\title{
Analysis of fire spread across a two-dimensional ridge under wind conditions
}

\author{
Jorge Raposo ${ }^{\text {a }}$ Salvatore Cabiddu ${ }^{\text {b }}$ Domingos X. Viegas ${ }^{\text {a }}$; Michele Salis ${ }^{\text {c,d }}$; Jason Sharples ${ }^{\text {e }}$ \\ ${ }^{a}$ ADAI/CEIF, University of Coimbra, Rua Luís Reis dos Santos, Coimbra 3030-788, Portugal. \\ jorge.raposo@dem.uc.pt \\ ${ }^{b}$ Sardinia Forest Service (CFVA), Italy; \\ ${ }^{c}$ University of Sassari, Department of Science for Nature and Environmental Resources (DIPNET), \\ Italy; \\ ${ }^{d}$ Euro-Mediterranean Center on Climate Changes (CMCC), IAFENT Division of Sassari, Italy; \\ ${ }^{e}$ University of New South Wales, Australia
}

\begin{abstract}
Laboratory scale investigation of a fire spreading on the windward face of a triangular section hill of variable shape with wind perpendicular to the ridgeline was performed. The work confirmed previous observations that the fire enlarges its lateral spread after reaching the ridgeline entering the leeward face with a much wider front. Reference fire spread velocities were measured and analyzed putting in evidence the importance of the dynamic effect due to flow velocity and its associated horizontal axis separation vortex strength without great dependence on hill geometry. A similar analysis performed to some real fires confirmed the same trend as was observed in the laboratory scale.
\end{abstract}

Keywords: fire channeling; lateral fire spread; horizontal vortices

\section{Introduction}

Predicting fire spread and behavior is one of the main challenges in forest fire research. It is widely recognized that wind, topography and fuels are the dominant factors affecting forest fire spread (Viegas 2004). The joint interactions among environmental factors and fire front influence fire propagation in various ways, particularly in areas with complex topography. In such conditions, many fatal accidents have been reported by a number of studies in different areas of the world. In fact, the interaction between wind, topography and fire front may lead to unusual patterns of fire spread that may surprise fire managers. An example of such a pattern occurs when a fire spreads across a two dimensional hill with wind blowing nearly perpendicular to the ridgeline. Pyrogenic vorticity, which manifests on the lee side of the ridge, produces a lateral enlargement of the fire that will then spread with a much wider front on that face of the hill and from then on (Simpson et al. 2013). This problem was first identified by McRae (2004) and it was analyzed by Sharples et al. (2011) and Sharples et al. (2012). A laboratory scale experimental research on this problem was carried out by the present authors for the case of a fire spreading upslope on the leeward face of the hill (Sharples et al. 2011). The interaction of the fire's plume with ambient horizontal vorticity near the top of this slope produced a lateral spread of the fire when it reached the ridgeline. This effect was confirmed in the numerical study presented by Simpson et al. (2013). In the above case the fire did not spread on the windward face and therefore this is possibly not the most interesting case to be analyzed.

In this paper the case of a fire spreading on the windward face of a two dimensional hill and its lateral spread at the ridgeline is analyzed. Laboratory scale experiments were performed in the large Combustion Tunnel of the University of Coimbra for various sets of hill configurations and flow velocities. Particular attention was given to the analysis of the lateral spread of the fire, and two models are proposed to estimate the relative growth rate of fire on both sides of the hill as a function of flow velocity and upslope non dimensional rate of spread. Our results put in evidence that the fire lateral growth is mainly due to the vortex flow dynamics, given its direct relationship with the dynamic 
pressure of the flow. Moreover, we analyzed three case studies in which lateral fire growth in similar topographic and flow conditions were documented obtaining the same trend on the parameters variation as at laboratory scale.

\section{Methods and Material}

\subsection{Physical problem}

We consider a two dimensional hill with a low radius of curvature ridgeline subject to atmospheric flow with a reference velocity $U$ that is assumed to be perpendicular to the ridgeline of the hill. We consider that the fuel bed is homogeneous and has uniform properties in the entire area of interest. In the present analysis we exclude crown fire spread and spot fire occurrence. The windward face (face $A$ in Figure $1 a$ ) has an average inclination angle $\alpha_{1}$ and the leeward face (face $B$ in Figure $1 b$ ) has an average inclination angle $\alpha_{2}$.

The wind flow will develop along face $A$ as a turbulent boundary layer with increasing velocity from the bottom to its top. At the ridge of the hill, depending on the radius of curvature, the Reynolds number of the flow and its turbulence intensity, the flow may separate forming a horizontal axis vortex and reattaching downslope in face $B$. The shape and extension of this separation zone is very much dependent on the incident flow properties and on hill geometry. If the radius of curvature of the ridge is very small, we are in the presence of a sharp ridge like in the case of a bluff body. In this configuration flow separation will certainly occur, because theoretically the flow velocity at the edge of a convex dihedral is equal to infinity, regardless of the Reynolds number. In nature these situations are not uncommon, so we took into consideration this condition in order to avoid dependence on flow Reynolds number and consequently on scale effects.

The complex flow produced around two dimensional hills immersed in a turbulent boundary layer has been studied by Ferreira (1995), among others. Even in the relatively simple cases of sinusoidal or triangular cross sections, the flow topology in the absence of fire is not simple and there is not a uniquely defined reference velocity to characterize this flow. In numerical or experimental studies in which the imposed flow is either uniform or has a well-defined boundary layer profile it is relatively easy to define a characteristic flow or wind velocity, but this is not the case in full scale situations for which other parameters may be required to characterize the flow (cf. Viegas and Neto, 1991).

With reference to Figure $1 a$, we assume that there is a fire starting at a point $O_{1}$ in face $A$ and spreading upslope along this face, with favorable wind until it reaches the ridgeline. In the limit this fire may have started before, but in that case it is assumed that it reaches this face with a relatively narrow fire front. It is observed that when the fire reaches the ridge and starts to descend face $B$ it begins to spread laterally, with a rate that is much larger than the one it had on the windward face. This process has been observed in several real fires and is corroborated by numerical simulations and laboratory experiments like the present ones. Simpson et al. (2013) demonstrated that the lateral spread results from the interaction between the fire's plume and the horizontal vorticity due to flow separation near the top of the ridge. This interaction generates vertical vorticity on the fire's flanks, which in turn generates a lateral flow in the immediate lee face of the ridge. For this reason this phenomenon is appropriately designated by Simpson et al. (2013) as "Vorticity-driven Lateral Spread (VLS)".

The analysis of the enhanced lateral spread of the fire on both sides of the hill is the main purpose of this study.

\subsection{Test configuration}

In the present study we consider a two dimensional hill of triangular cross section, meaning that both faces $A$ and $B$ are plane surfaces. The inclination angles are $\alpha_{1}$ and $\alpha_{2}$ respectively for the windward face $A$ and for the leeward face $B$ (Figure 1a). The two faces intersect as a sharp ridge line. A reference Cartesian system is defined in the following way. The axis $O X$ is parallel to the horizontal direction 
and has its origin at the edge of the plane surface on which the hill is based; $O Z$ axis is vertical and $O Y$ axis is also horizontal and parallel to the ridgeline of the hill.

Wind with a reference velocity $U$ flows perpendicular to the ridgeline and in these conditions a vertical plane containing the $O X$ axis is a plane of symmetry of the fire. The oncoming flow velocity may vary with $z$ but not with $y$. We assume that a point source fire is ignited at point $\mathrm{O}_{1}$ at a distance $a=50 \mathrm{~cm}$ from the base of the hill in the windward face. We define (cf. Figure $1 b$ ) the following distances travelled by the fire during its spread:

$s_{1 \mathrm{~A}}$ is the distance from the fire origin to the head of the fire along axis $O_{S 1}$ that is a symmetry line on face $A$;

$s_{2 \mathrm{~A}}$ is the distance from the fire origin $O_{1}$ to the back fire along the same axis but measured in the downslope direction (it is considered as a positive quantity);

$s_{3 \mathrm{AR}}$ is the distance measured from the $O_{S 1}$ axis to the right flank of the fire on face $A$, measured along $O_{S 3 A}$ axis that is an horizontal axis placed at a distance $b=20 \mathrm{~cm}$ from the ridgeline;

$s_{3 A L}$ is a similar distance measured to the left flank of the fire line;

$s_{1 \mathrm{~B}}$ is the distance from the ridgeline to the head of the fire along axis $O_{S 1 A}$ that is a symmetry line on face $B$ (with descending fire);

$s_{3 \mathrm{BR}}$ is the distance measured from the $O_{S 1 B}$ axis to the right flank of the fire on face $B$, measured along $O_{S 3 A}$ axis that is an horizontal axis placed at a distance $c=10 \mathrm{~cm}$ from the ridgeline;

$s_{3 \mathrm{BL}}$ is a similar distance measured to the left flank of the fire line;

We define the average value of the rate of spread along each one of the seven directions that were defined above as the slope of a linear fit of the function $s_{i}(t)$. This simplification is only acceptable if there are no consistent variations of the rate of spread (ROS) and it implies that the fire is spreading in a quasi-steady state, which may not be valid in all cases (cf. Viegas 2004).

Given the symmetry of the fire, we assume that $s_{3 \mathrm{AR}}=s_{3 \mathrm{AL}}$ and $s_{3 \mathrm{BR}}=s_{3 \mathrm{BL}}$. Therefore we only need to consider five relevant ROS to characterize the problem. The fire will spread upslope with a ROS $R_{1 A}$, downslope with a $\operatorname{ROS} R_{2 A}$ and laterally with a ROS $R_{3 A}$ (cf. figure 1b)). After reaching the ridgeline, the fire will spread downslope on face $B$ with a ROS $R_{1 B}$, and laterally with a ROS $R_{3 B}$.

In order to minimize the effect of small variations of fuel bed properties, namely moisture content, following Viegas and Neto (1991) we use the non-dimensional ROS (NDROS) values given by:

$$
R^{\prime}=\frac{R}{R_{o}}
$$

In the present analysis we shall use the following five NDROS to characterize the spread of the fire along its main directions.

$\begin{array}{ll}\text { Upslope NDROS in face A: } & R^{\prime}{ }_{1 A}=\frac{R_{1 A}}{R_{0}} \\ \text { Downslope NDROS in face A: } & R^{\prime}{ }_{2 A}=\frac{R_{2 A}}{R_{0}} \\ \text { Lateral NDROS in face A: } & R^{\prime}{ }_{3 A}=\frac{R_{3 A}}{R_{0}} \\ \text { Downslope NDROS in face B: } & R^{\prime}{ }_{1 B}=\frac{R_{1 B}}{R_{0}} \\ \text { Lateral NDROS in face B: } & R^{\prime}{ }_{3 B}=\frac{R_{3 B}}{R_{0}}\end{array}$

Given the importance of comparing the relative growth of lateral fire spread in faces $A$ and $B$ we shall use also the following non-dimensional parameter:

$$
k_{3}=\frac{R_{3 B}}{R_{3 A}}
$$




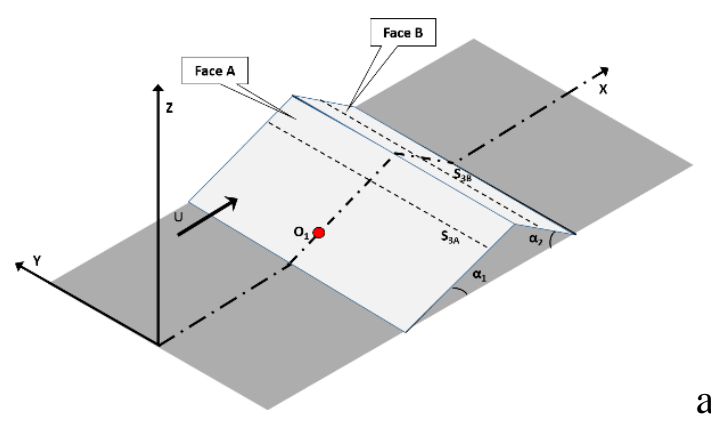

a)

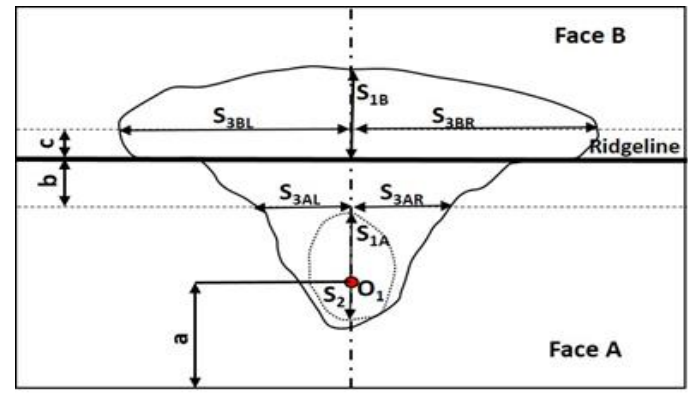

b)

Figure 1. (a) Schematic representation of the fire; (b) Detail of the fire spread analysis.

\section{Experimental Study}

The experimental study was performed at the Combustion Tunnel TC 3 of the Fire Research Laboratory of the University of Coimbra in Lousã (Portugal). The Tunnel has a working section of $6 \times 8 \mathrm{~m}^{2}$ and a maximum flow velocity of $7 \mathrm{~m} \mathrm{~s}^{-1}$ (figure 2). A model of the two dimensional hill composed of two metallic plates hinged at the ridge line was used in the experiments. The width of the model is $4 \mathrm{~m}$, and the length of faces $A$ and $B$ are $1.5 \mathrm{~m}$ and $1.0 \mathrm{~m}$ respectively. The fuel bed for the experiments was composed by dry particles of straw with a constant load of $0.6 \mathrm{~kg} \mathrm{~m}^{-2}$ (dry basis). Moisture content of the fuel was measured for each test or groups of tests with an A\&D ML50 Moisture Analyzer. A reference test to measure the basic ROS $R_{o}$ in no slope and no wind conditions was made in each test session. The corresponding values are given in Table 1.

The configuration of the model in each series of tests was adjusted fixing the value of $\alpha_{1}$ of face $A$. Given the model construction, the slope $\alpha_{2}$ of face $B$ depended on $\alpha_{1}$. Three values of $\alpha_{1}$ were used in the present tests: $20^{\circ}, 25^{\circ}$ and $30^{\circ}$. The resulting values of $\alpha_{2}$ were respectively close to: $30^{\circ}, 40^{\circ}$ and $50^{\circ}$. For each hill configuration five tests were performed with values of $U$ equal to: $0,1,2,3$ and $4 \mathrm{~m}$ $\mathrm{s}^{-1}$. The values of $\alpha_{1}$ and $\alpha_{2}$ and flow velocity used in each test are reported in Table 1.

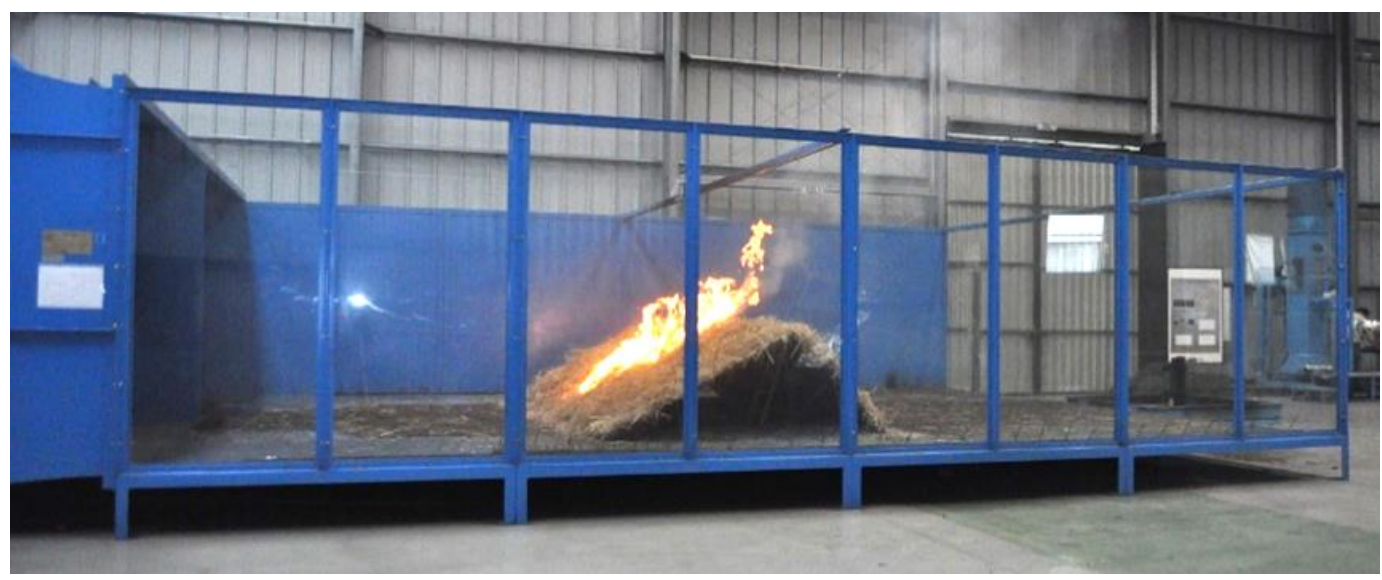

Figure 2. General view of the Combustion Wind Tunnel of the Forest Fire Research Laboratory of the University of Coimbra.

A point fire was ignited at point $\mathrm{O}_{1}$ (Figure $1 a$ and $\left.1 b\right), 0.5 \mathrm{~m}$ above the base of face $A(a=0.5 \mathrm{~m})$ and then the flow was turned on for the pre-adjusted velocity. Two video cameras, one IR camera and several digital photo cameras were used to record fire spread on each face of the hill. The images obtained were processed using a software developed by the ADAI team to analyze fire evolution and determine ROS values along relevant directions. Though in some cases the fire spread was not steady (cf. Viegas, 2006), we assumed that the ROS was constant along each spread direction $\left(s_{i}\right)$ that was 
considered, and therefore the corresponding average value of ROS was estimated as the slope of a straight line fitted to the plot of $\left(s_{i}, t\right)$ using between four and ten data points. Lateral ROS $R_{3 A}$ was measured along a horizontal line $0.3 \mathrm{~m}$ from the ridgeline, and $R_{3 B}$ was measured on face $B$ along a horizontal line $0.1 \mathrm{~m}$ from the ridgeline. Although the test configuration was nominally symmetrical, in order to assess this condition the lateral spread was measured separately for both sides (right and left) in each face: $R_{3 A R}$ and $R_{3 A L}$, for face $A$ and $R_{3 B R}$ and $R_{3 B L}$ for face $B$. As good symmetry conditions were found in the performed experiments the values of $R_{3 A}$ and $R_{3 B}$ given in Table 1 and that are used in subsequent analysis are the average of both left and right side estimates.

Table 1. Parameters of Tests performed in the present study

\begin{tabular}{ccccccccccc} 
Ref. & $\alpha_{1}$ & $\alpha_{2}$ & $U$ & $m_{f}$ & $R_{o}$ & $R_{I A}$ & $R_{l B}$ & $R_{2}$ & $R_{3 A}$ & $R_{3 B}$ \\
& $\left({ }^{o}\right)$ & $\left({ }^{o}\right)$ & $\left(m s^{-1}\right)$ & $(\%)$ & $\left(\mathrm{cm} \mathrm{s}^{-1}\right)$ & $\left(c m s^{-1}\right)$ & $\left(c m s^{-1}\right)$ & $\left(c m s^{-1}\right)$ & $\left(c m s^{-1}\right)$ & $\left(c m s^{-1}\right)$ \\
\hline VH 01 & & & 2 & 13.6 & 0.73 & 4.75 & 0.81 & 0.77 & 1.12 & 3.15 \\
VH 02 & & & 3 & 15.5 & 0.69 & 4.87 & 1.09 & - & 1.49 & 4.38 \\
VH 03 & \multirow{2}{*}{25} & 40 & 4 & 12.5 & 1.09 & 7.88 & 1.81 & 0.18 & 1.04 & 6.79 \\
VH 04 & & & 1 & 12.5 & 1.09 & 5.79 & 0.81 & 0.69 & 3.40 & 2.27 \\
VH 05 & & & 0 & 13.1 & 0.84 & 1.40 & 0.34 & 0.63 & 1.58 & 0.82 \\
\hline VH 06 & & & 2 & 13.1 & 0.84 & 3.74 & 1.29 & 0.68 & 1.52 & 2.59 \\
VH 07 & & & 3 & 9 & 0.73 & 10.35 & 1.18 & 0.31 & 2.36 & 4.29 \\
VH 08 & \multirow{2}{*}{30} & \multirow{2}{*}{50} & 0 & 9 & 0.73 & 2.10 & 0.96 & 0.59 & 1.55 & 1.59 \\
VH 09 & & & 1 & 14.8 & 1.00 & 2.11 & 0.63 & 0.79 & 1.07 & 1.35 \\
VH 10 & & & 4 & 14.8 & 1.00 & 7.38 & 2.84 & 0.55 & 1.83 & 9.63 \\
\hline VH 11 & & & 2 & 14.8 & 1.00 & 9.90 & 1.09 & 0.33 & 1.59 & 3.60 \\
VH 12 & & & 3 & 10.1 & 0.92 & 8.18 & 1.65 & 0.45 & 1.59 & 4.40 \\
VH 13 & \multirow{2}{*}{20} & \multirow{2}{*}{30} & 1 & 10.0 & 0.92 & 2.66 & 0.69 & 0.31 & 1.62 & 1.76 \\
VH 14 & & & 0 & 10.0 & 0.92 & 1.45 & 0.76 & 0.79 & 1.39 & 1.55 \\
VH 15 & & & 4 & 10.0 & 0.92 & 9.85 & 3.63 & 0.53 & 1.94 & 8.71
\end{tabular}

\section{Case Studies}

In order to assess the validity of present results obtained at laboratory scale we used data from some real fires in which lateral fire growth most probably due to channeling or horizontal axis formation on the lee side of a ridge have been observed. Some of them were already mentioned and described by Sharples et al. (2012).

\subsection{Fire of Broken Cart}

During the large fires that affected the city of Canberra (Australia) on $18^{\text {th }}$ January 2003, various cases of VLS were observed (McRae 2004). Among these cases we selected the event of the Broken Cart Fire that is described by McRae (2004). 


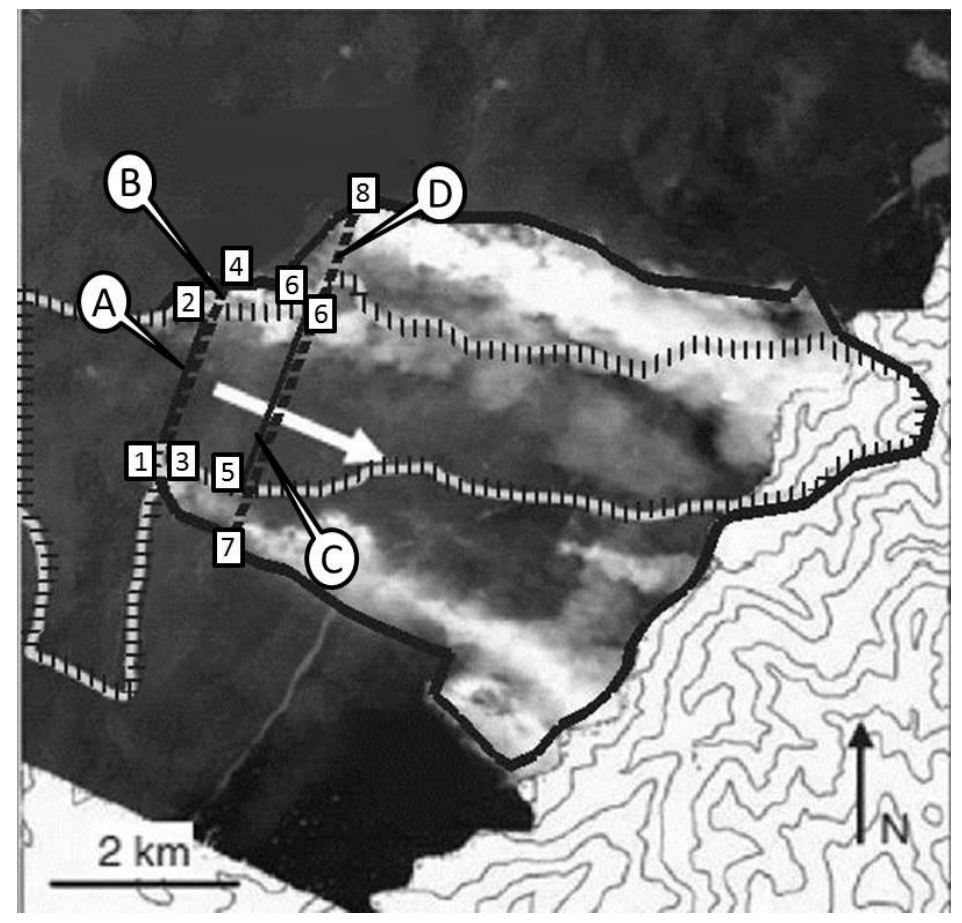

Figure 3. Schematic view of Broken Cart Fire (adapted from Sharples et al. (2012)).

In Figure 3 the white line with black dashes corresponds to 14:00 hours and the black bold line represents the fire at 15:09. The white bold arrow indicates the main spread direction due to the synoptic wind. Line A that is limited by points 1 and 2 represents the width of the main fire front before crossing the ridge at 14:00. Line B located between points 3 and 4, plotted with dashed bold line refers to the width perpendicular to the main spread direction before the ridge crossing at 15:09. The difference between the lengths of segments $\mathrm{A}$ and $\mathrm{B}$ divided by the time lapse gives the rate of enlargement of the fire front perpendicular to the main spread direction here designated as $R_{3 A}$.

The measurements made after the fire crossed the ridge correspond to line $\mathrm{C}$ delimited by points 5 and 6 at 14:00 and line D between points 7 and 8 at 15:09. The rate of enlargement of the fire front after crossing the ridge that results from the analyses of these two lines corresponds to $R_{3 B}$. The coefficient that gives the ratio of enlargement between side A (before the ridgeline) and side B (after crossing the ridgeline) is designated as $k_{3}$. The corresponding values are given in Table 2 .

Table 2. Parameters of Case Studies analyzed in the present study

\begin{tabular}{cccccccc} 
Case & $\begin{array}{c}R_{o} \\
\left(m s^{-1}\right)\end{array}$ & $\begin{array}{c}R_{I A} \\
\left(m^{-1}\right)\end{array}$ & $\begin{array}{c}R_{3 A} \\
\left(m^{-1}\right)\end{array}$ & $\begin{array}{c}R_{3 B} \\
\left(m^{-1}\right)\end{array}$ & $\begin{array}{c}U \\
\left(m^{-1}\right)\end{array}$ & $\begin{array}{c}R^{\prime}{ }_{I A} \\
-\end{array}$ & $\begin{array}{c}k_{3} \\
-\end{array}$ \\
\hline Broken Cart & 0.06 & 0.69 & 0.12 & 0.42 & 9 & 11.60 & 3.59 \\
Sa Costa & 0.15 & 0.43 & 0.39 & 0.64 & 4 & 2.87 & 1.64 \\
Golfo Aranci & 0.06 & 0.54 & 0.18 & 0.68 & 10 & 9.69 & 5.70
\end{tabular}

\subsection{Fire of Sa Costa}

An interesting case study involving the fire spread process that is being analyzed occurred in Sardinia (Italy) on the $5^{\text {th }}$ and $6^{\text {th }}$ August 2010. This fire was reported in Cabiddu et al. 2010, and a brief description is presented here.

This fire is designated as Sa Costa and it occurred near the village of Jerzu, in the Province of Ogliastra, Eastern Sardinia. 


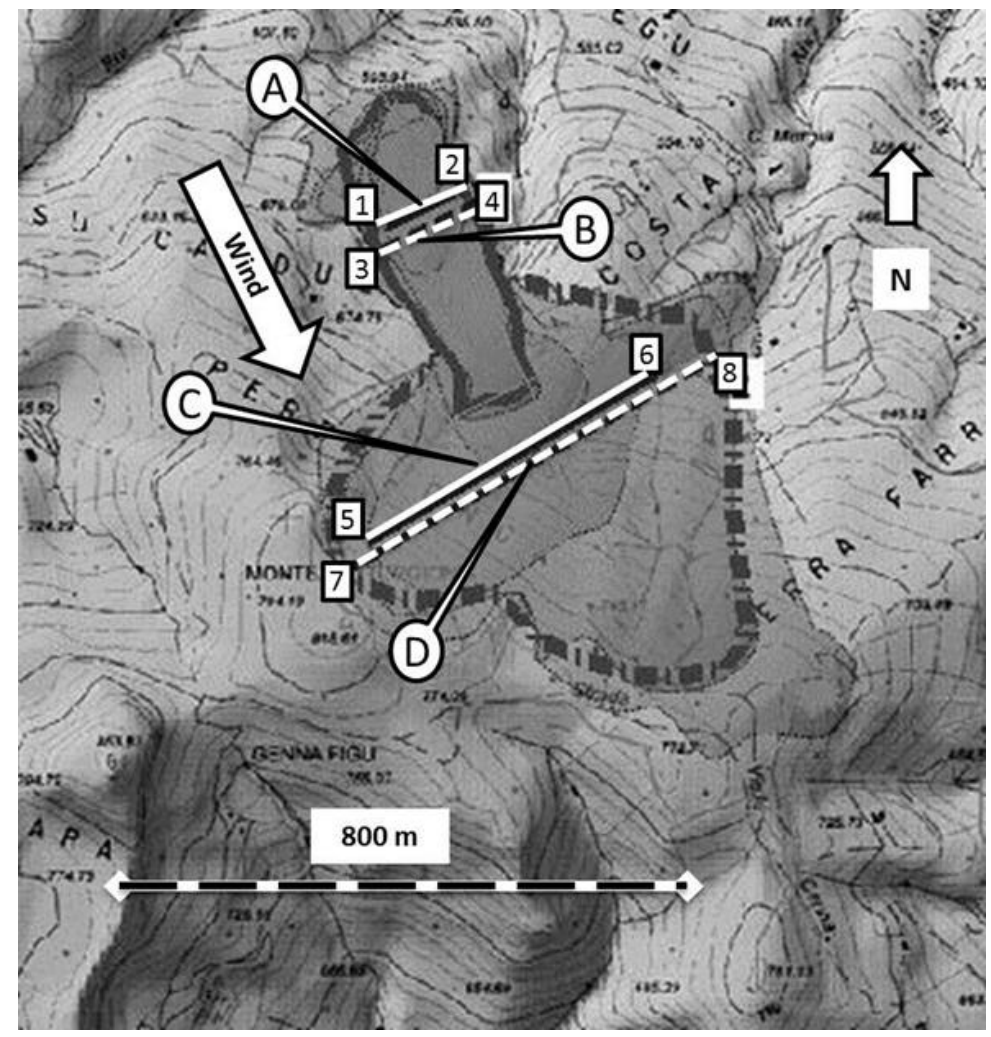

Figure 4. Spread of Sa Costa fire, in Eastern Sardinia, on the 5th of August of 2010.

In Figure 4 the analysis performed with the plots of the fire perimeter at different times are shown. The blue bold line corresponds to 17:05 and the dashed bold line represents the fire perimeter at 17:40. The wind direction was $320-330^{\circ}$.

The line A, plotted in bold white that is limited by points 1 and 2, represents the width of the main fire front before crossing the ridge at 17:05. Line B, located between points 3 and 4, refers to the width perpendicular to the main spread direction before the ridge crossing at 17:40. The difference between the lengths of the segments A and B divided by the lapse of time gives the rate of enlargement of the fire front perpendicular to the main spread direction here designated as $R_{3 A}$.

\subsection{Fire of Golfo Aranci}

The fire of Golfo Aranci occurred in Northeast Sardinia (Italy), near the town of Olbia, on the $24^{\text {th }}$ June of 2013. The fire started at 14:43, the wind direction and intensity was practically constant and wind velocity decreased from 40 to $30 \mathrm{~km} \mathrm{~h}^{-1}$ over the duration of the fire.

When the fire reached a ridge with NNW-SSE direction, almost perpendicular to the wind direction, it spread laterally along the lee side of the ridge as it is shown in figure 5. Using the isochrones of fire spread that were provided by the Sardinia Forest Service, we estimated the relevant ROS values that are indicated in Table 2. 


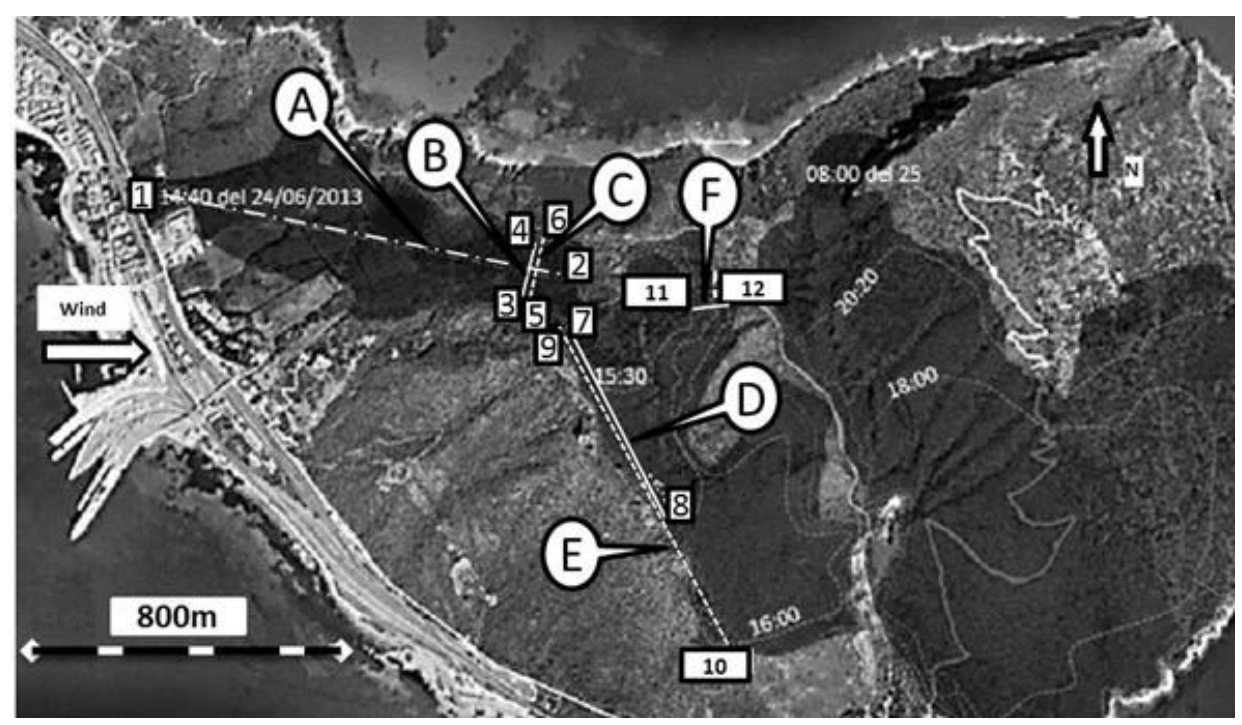

Figure 5. Spread of fire of Golfo Aranci in Sardinia, on the 24 $4^{\text {th }}$ June 2013.

By the analyses of the isochrones represented by the white lines and consequently of the fire perimeters defined at 14:40, 15:30 and 16:00 the rate of spread of the main fire front in side A, that is designated as $R_{1 A}$ was estimated. This calculation was based on the measurement of the length of line A located between points 1 and 2 . The rate of enlargement of the fire front in side $\mathrm{A}, R_{3 A}$, corresponds to the difference of lengths of the segments B and $C$ divided by the lapse of time. Line B is defined between the points 3 and 4 , and line $\mathrm{C}$ is defined by points 5 and 6 .

The rate of enlargement in side $\mathrm{B}, R_{3 B}$ was estimated by the analysis of the relative growth of line $\mathrm{E}$ in relation to line $\mathrm{D}$ in the lapse of the time. Line $\mathrm{D}$ is limited by the boundary points 7 and 8 and line $\mathrm{E}$ is defined by points 9 and 10 .

Finally line F, defined by points 11 and 12 and corresponding to a downslope fire spread, was used to estimate the basic rate of spread for this fuel bed in the absence of slope and wind.

\section{Results and Discussion}

\subsection{Fire Contours}

The analysis of the fire contours obtained in each laboratorial test and the respective shapes for the 15 tests performed are presented in figures 6,7 and 8 . In these figures face $A$ is below and face $B$ is above. The values in the axis correspond to the actual dimensions of the hill model in meter. The ridgeline corresponds to the dotted horizontal line at $1.5 \mathrm{~m}$ from the bottom. The wind is blowing from the bottom to the up of the figure. 

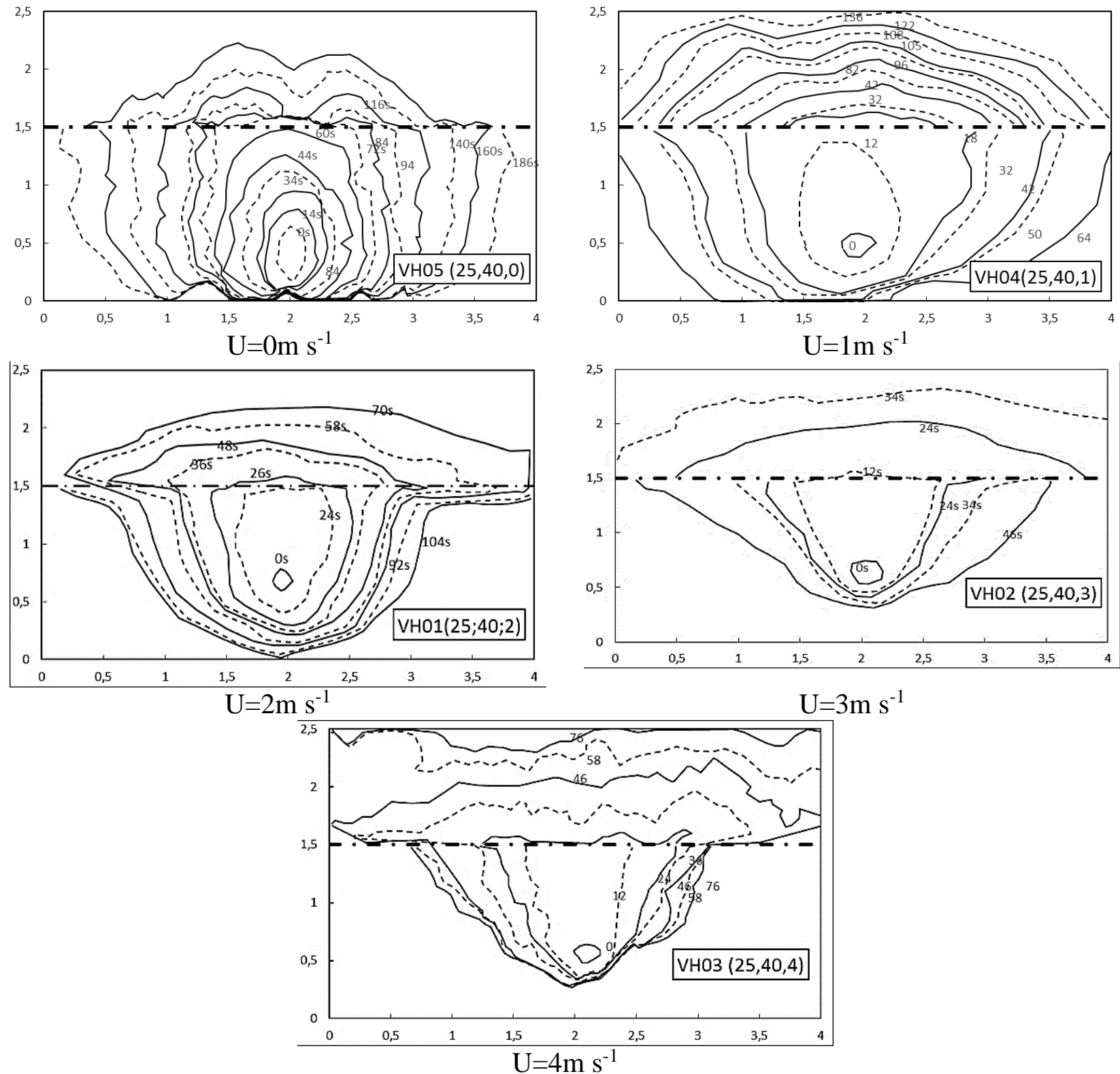

Figure 6. Fire line contours for tests with $\alpha_{1}=25^{\circ}$ and $\alpha_{2}=40^{\circ}$ for the indicated values of wind velocity.
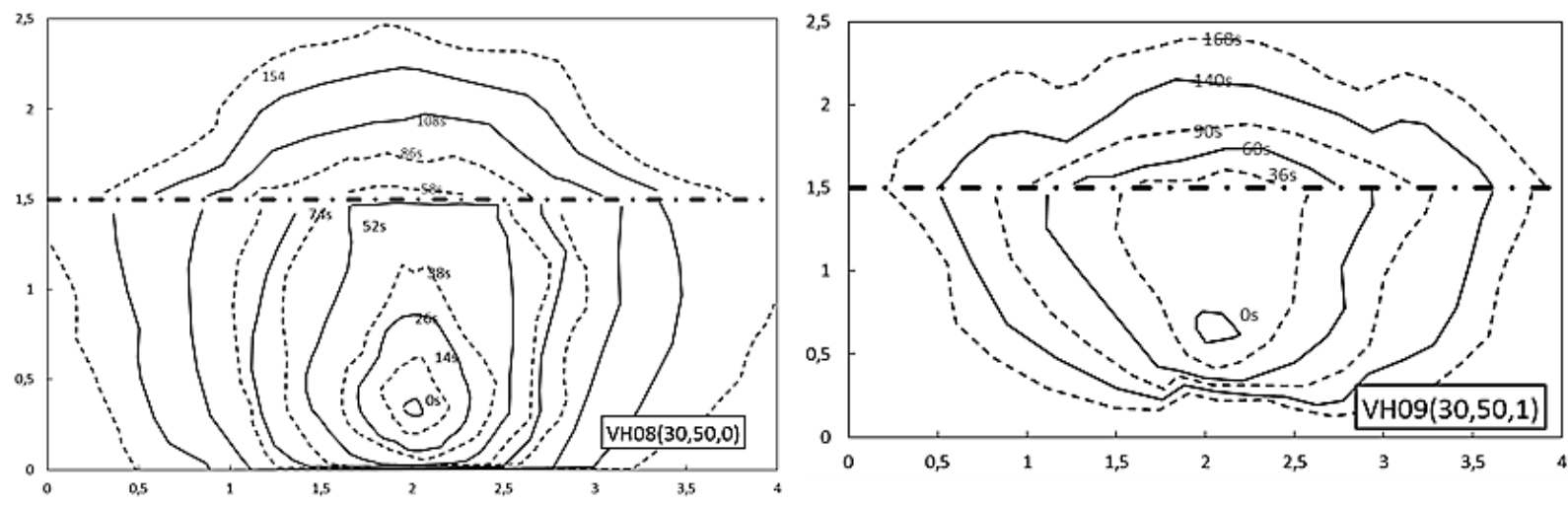

$\mathrm{U}=0 \mathrm{~m} \mathrm{~s}^{-1}$

$\mathrm{U}=1 \mathrm{~m} \mathrm{~s}^{-1}$ 

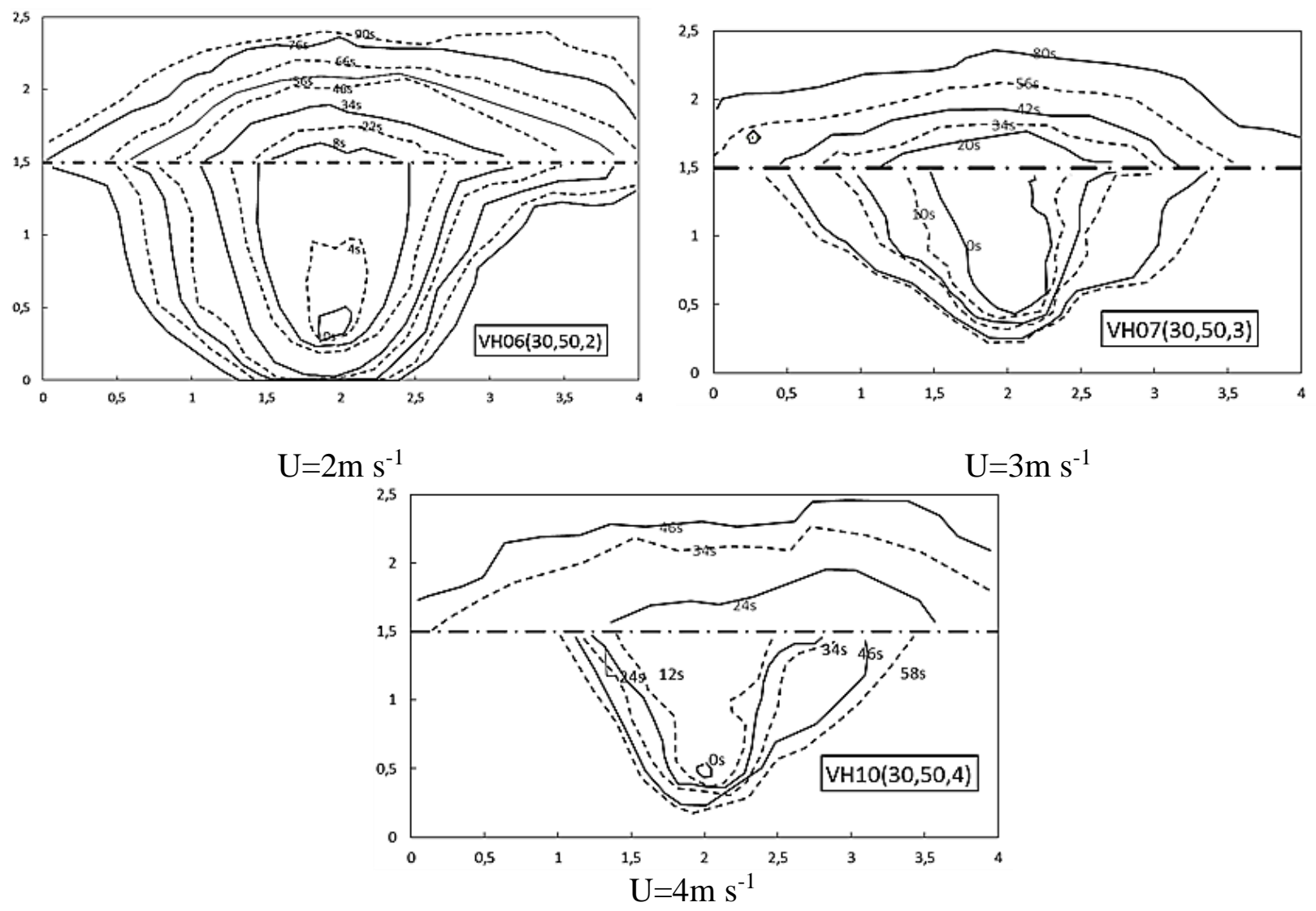

Figure 7. Fire line contour for tests with $\alpha_{1}=30^{\circ}$ and $\alpha_{2}=50^{\circ}$ for the indicated values of wind velocity
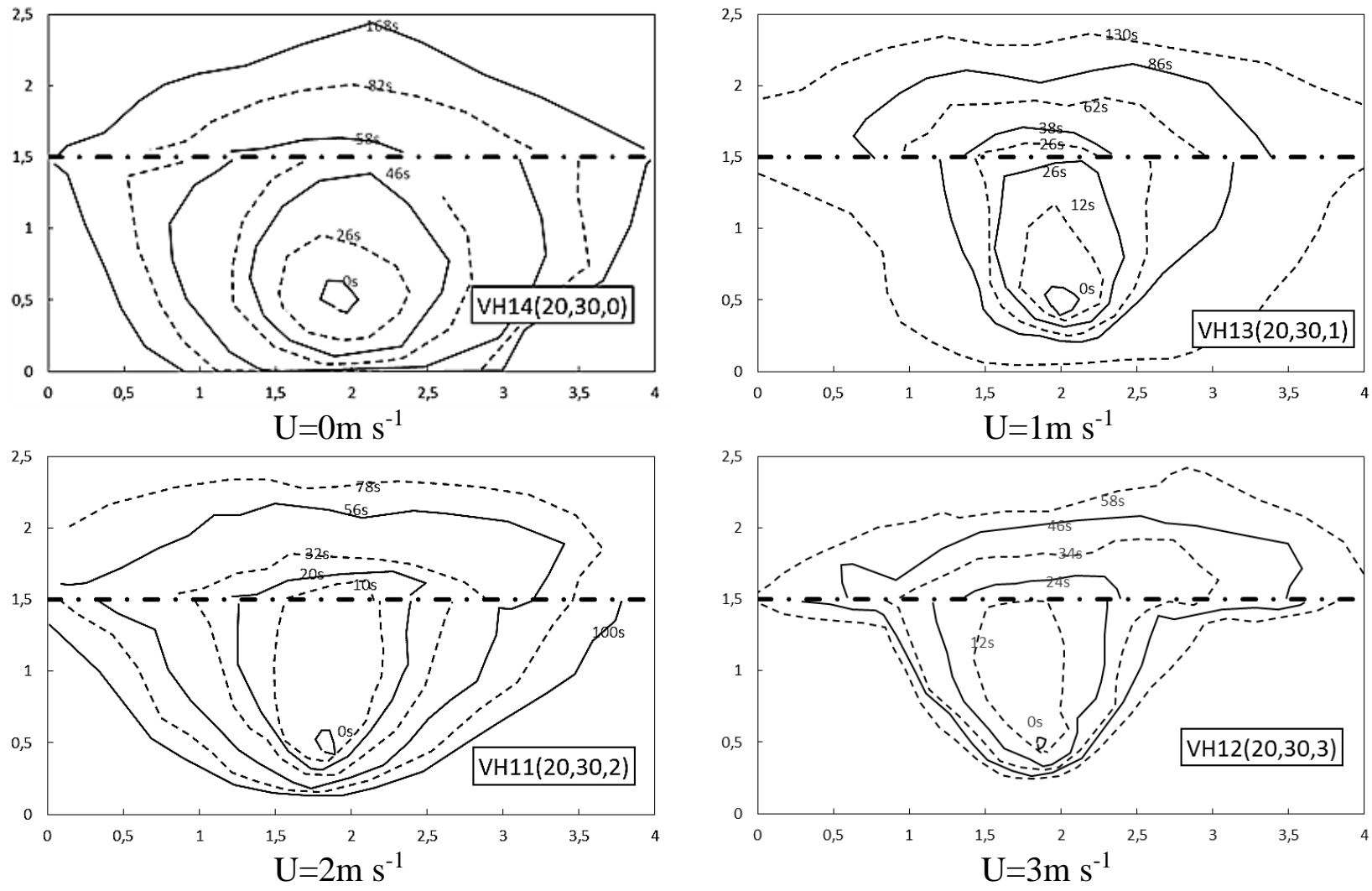


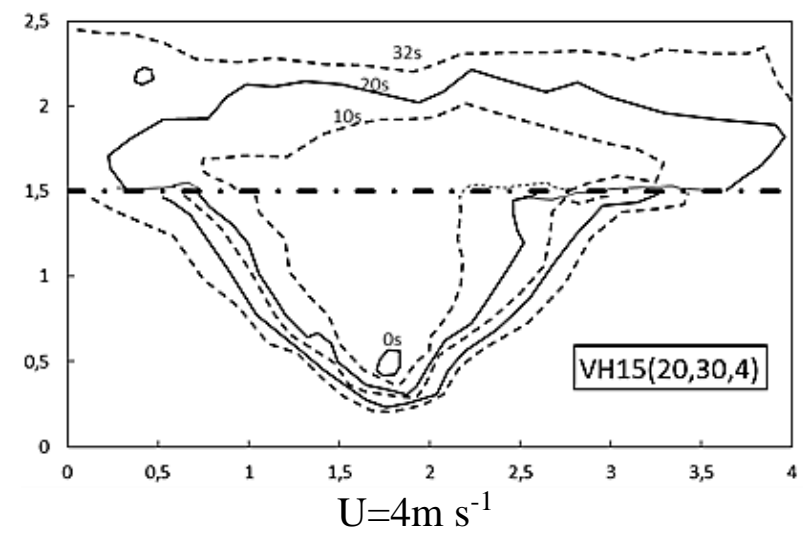

Figure 8. Fire line contour for tests with $\alpha_{1}=20^{\circ}$ and $\alpha_{2}=30^{\circ}$ for the indicated values of wind velocity

\subsection{Rate of spread along wind direction}

In Figure 9 the values of $R^{\prime}{ }_{1 A}$ show an increase approximately with the square of the reference flow velocity, but the dependence with slope angle $\alpha_{l}$ is not clear. The data points corresponding to the real fires follow the same trend but with a different value of the reference wind velocity.

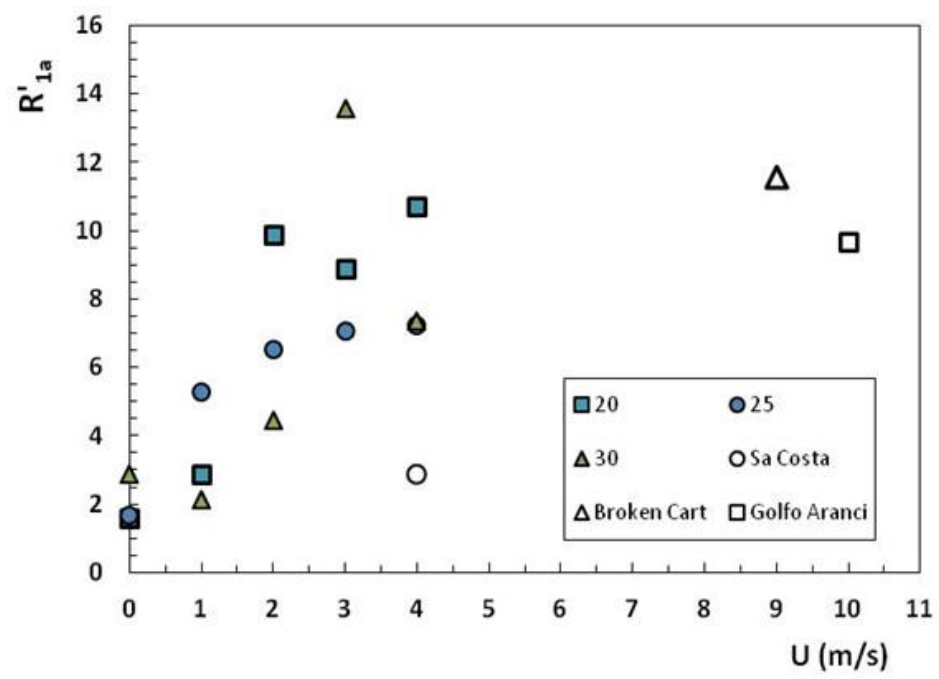

Figure 9. Evolution of $\mathrm{R}_{1 \mathrm{~A}}$ as a function of wind velocity for the three configurations tested and for Sa Costa, Broken Cart and Golfo Aranci Fires.

As could be expected, the values of $R^{\prime}{ }_{2}$, shown in Figure 10, corresponding to the tail of the fire spreading downslope and with contrary wind, are quite low. These values are usually lower than 1.0 and tend to decrease with increasing wind velocity. In some cases it was observed that the fire would extinguish and fire spread ceased.

The values of $R^{\prime}{ }_{1 B}$, corresponding to the average NDROS of the fire front descending the slope on face $B$ with favorable wind, which are shown in Figure 11, show a practically linear increase with wind velocity with no marked dependence on the hill geometry. 


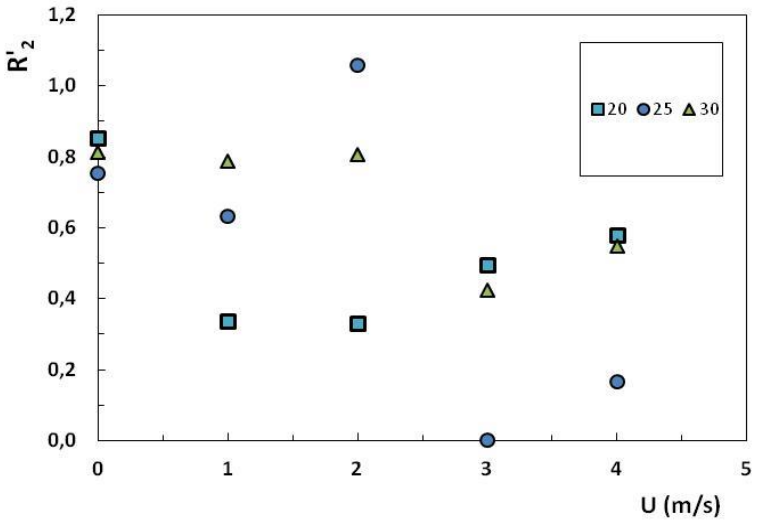

Figure 10. Evolution of R'2 as a function of wind velocity for the three configurations tested

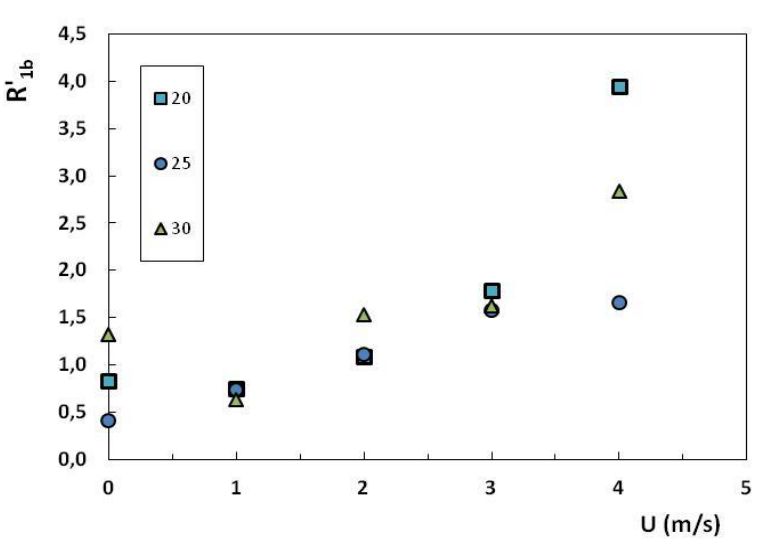

Figure 11. Evolution of $\mathrm{R}^{\prime} 1 \mathrm{~B}$ as a function of wind velocity for the three configurations tested

\subsection{Lateral Rate of spread}

The analysis of lateral fire spread is of great interest in the context of the present work. In Figure 12 and 13 we show the results obtained for $R{ }_{3 A}$ and $R{ }_{3 B}^{\prime}$ respectively. As can be seen in Figure 10, the average rate of lateral growth of the fire on face $A$ is relatively small and does not seem to depend very much either on the slope angle $\alpha_{1}$ or on the flow velocity. The corresponding value of 2.6 for the Sa Costa Fire is within the range of our laboratory experiments.

The lateral growth of the fire in face $B$ is performed with a NDROS $R$ ' $3 B$ that is usually larger than $R^{\prime}{ }_{3 A}$ and shows a marked increase with flow velocity, with no clear dependency on hill geometry. The value of 4.26 for Sa Costa fire is slightly above our trend and seems to correspond to a slightly higher value of the reference wind velocity, possibly closer to $2.5 \mathrm{~ms}^{-1}$.

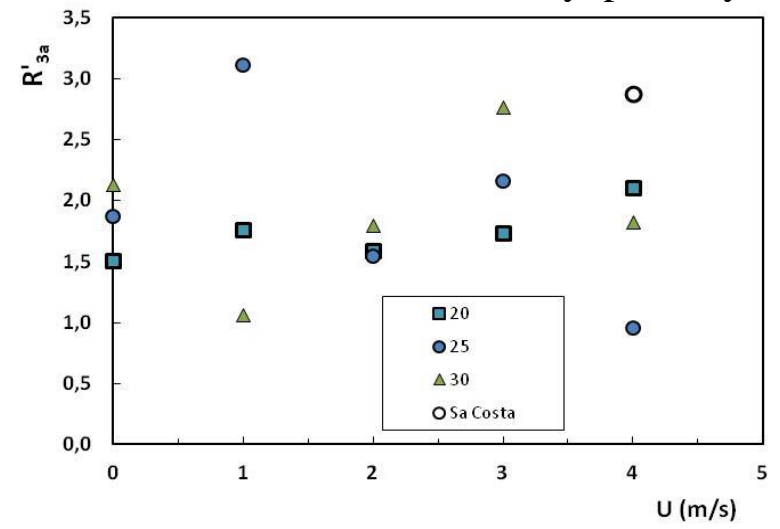

Figure 12. Evolution of $\mathrm{R}_{3 \mathrm{~A}}$ as a function of wind velocity for the three configurations tested. The point corresponding to Sa Costa fire is shown in the figure.

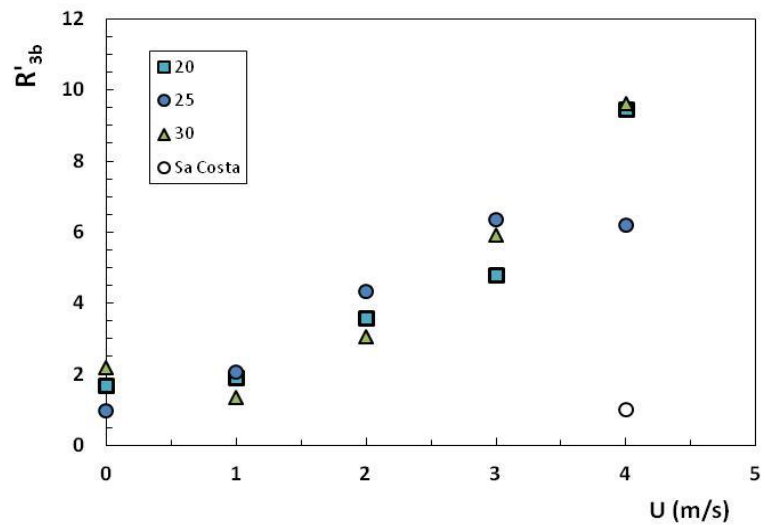

Figure 13. Evolution of $\mathrm{R}^{3}$ зв as a function of wind velocity for the three configurations tested. The point corresponding to Sa Costa fire is shown in the figure.

\subsection{Evolution of lateral fire growth ratio $\mathrm{k} 3$}

Parameter $k_{3}$, introduced in equation [7] provides a comparison between the rates of lateral growth of the fire in the windward and leeward faces of the hill (faces $A$ and $B$ respectively).

The evolution of $k_{3}$ as a function of wind velocity is shown in Figure 14. As can be seen, $k_{3}$ values increase with the square of $U$ and exhibit only a small dependence on the hill geometry in the present set of test conditions. The values of $k_{3}$ obtained for the real fires are shown in Figure 14 as well. A good model to estimate $k_{3}$ as a function of $U$ is obtained with the following equation:

$$
k_{3}=1+a_{3} \cdot U^{2}
$$


The values of coefficient $a_{3}$ and of the corresponding $r^{2}$ fitness parameter for each configuration and for the entire set of laboratory data, excluding two cases for which $k_{3}<1$, are given in Table 3 . The value of $a_{3}=0.041$ obtained for the field cases is much lower than the average value obtained for laboratory experiments $\left(a_{3}=0.256\right)$. This difference can be explained by the already mentioned difficulty in defining a reference velocity for tests in combustion tunnels and for field cases. The ratio between the values of $a_{3}$ for laboratory and field cases indicates that the field reference velocity is approximately 2.5 times larger than the combustion tunnel velocity. Assuming that the velocity profile near the ground is logarithmic, this is equivalent to considering that the wind tunnel velocity is measured at the height of $1.5 \mathrm{~m}$ while the field reference wind velocity is measured at $10 \mathrm{~m}$ height.

Table 3. Parameters of Model to estimate $k_{3}$ as a function of flow velocity

\begin{tabular}{lcc}
\multicolumn{1}{c}{ Case } & $a_{3}$ & $r^{2}$ \\
\hline$\alpha_{1}=20^{\circ} ; \alpha_{2}=30^{\circ}$ & 0.217 & 0.972 \\
$\alpha_{1}=25^{\circ} ; \alpha_{2}=40^{\circ}$ & 0.321 & 0.850 \\
$\alpha_{1}=30^{\circ} ; \alpha_{2}=50^{\circ}$ & 0.230 & 0.894 \\
All Laboratory Tests & 0.256 & 0.859 \\
Field cases & 0.041 & 0.892
\end{tabular}

In our opinion, the result expressed by this model is quite relevant as it indicates that the relative rate of growth of lateral fire depends on the dynamic pressure that is proportional to the kinetic energy of the incident flow. This fact puts in evidence that the lateral growth of the fire is a consequence of the flow on the lee side of the ridge which is comprised of horizontal axis vorticity caused by flow separation at the ridge. Without disregarding the effects of the combustion energy added to the flow, this result shows clearly that the lateral growth of the fire is mainly a result of the vortex flow dynamics.

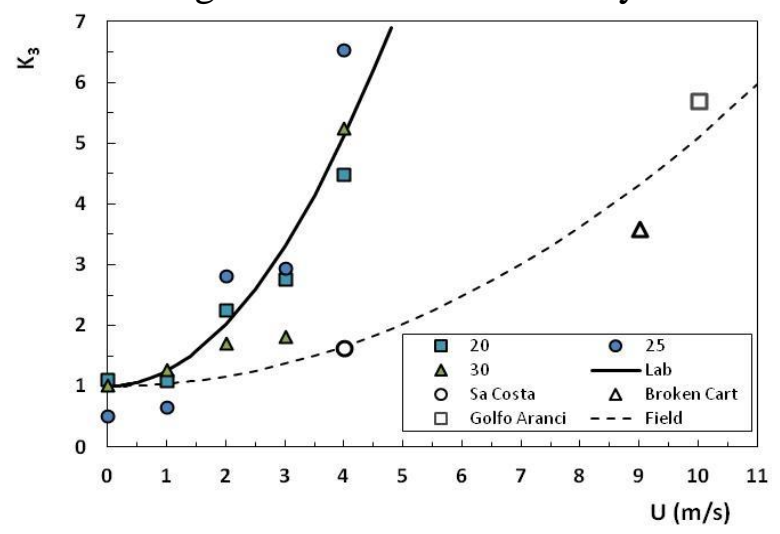

Figure 14. Evolution of $\mathrm{k}_{3}$ as a function flow velocity for laboratory tests and for the real fires. The two lines correspond to the present model for laboratory and field cases.

\section{Conclusion}

The experiments discussed above demonstrate that the interaction of a fire with wind flowing in complex terrain can give rise to dynamic mechanisms that can enlarge a fire front near the top of a crest. In addition, the main direction of fire propagation is different to the expected direction of fire spread.

The authors intend to extend this experimental program considering other hill configurations and the influence of fuelbed composition on the lateral spread parameters. The influence of wind direction in relation to the ridgeline will be analyzed as well. 


\section{Acknowledgements}

The authors wish to thank Portuguese Science Foundation for the support given to project Extreme under contract PTDC/EME-MFE/114343/2009 and for a PhD grant under contract SFRH / BD / 85557 / 2012. The support given by the Portuguese Company Rede Enérgetica Nacional to purchase and equip the Combustion Tunnel is also acknowledged. The participation of Dr. Cabiddu was supported by a grant from the Sardinia Region in the context of the Master PIROS program. J.J. Sharples is supported by an Australian Research Council Discovery Indigenous Award (IN130100038). Dr. Salis is supported by the Project "Modeling approach to evaluate fire risk and mitigation planning actions".

\section{Symbols}

\begin{tabular}{|c|c|c|}
\hline Symbol & Units & Description \\
\hline$\alpha_{1}$ & - & Inclination angle of windward face $A$ of the two dimensional hill \\
\hline$\alpha_{2}$ & - & Inclination angle of leeward face $B$ of the two dimensional hill \\
\hline $\mathrm{O}$ & - & Origin of reference Cartesian system \\
\hline $\mathrm{O}_{1}$ & - & Origin of the fire \\
\hline$O X$ & - & $\begin{array}{l}\text { Horizontal axis is parallel to the horizontal direction and has its origin at the edge of } \\
\text { the plane surface on which the hill is based }\end{array}$ \\
\hline $\mathrm{OY}$ & & Horizontal axis parallel to the ridgeline of the hill. \\
\hline $\mathrm{OZ}$ & & Vertical axis \\
\hline$U$ & $\mathrm{~m} \cdot \mathrm{s}^{-1}$ & Reference flow velocity \\
\hline$R$ & $m . s^{-1}$ & Rate of spread (ROS) \\
\hline$R_{o}$ & $\mathrm{~cm} \cdot \mathrm{s}^{-1}$ & Basic rate of spread of linear fire in the absence of slope and wind \\
\hline$R_{1 A}$ & $m . s^{-1}$ & Rate of spread perpendicular to the ridge in the face A driven by the wind \\
\hline$R_{l B}$ & m. $s^{-1}$ & Rate of spread perpendicular to the ridge in the face B driven by the wind \\
\hline$R_{2}$ & $m . s^{-1}$ & Rate of spread perpendicular to the ridge in the face $A$ against the wind \\
\hline$R_{3 A R}$ & m. $s^{-1}$ & Rate of enlargement of the fire front in the face $\mathrm{A}$ in the right direction \\
\hline$R_{3 A L}$ & $m . s^{-1}$ & Rate of enlargement of the fire front in the face $\mathrm{A}$ in the left direction \\
\hline$R_{3 A}$ & m. $s^{-1}$ & Average Rate of enlargement of the fire front in the face A \\
\hline$R_{3 B R}$ & $m . s^{-1}$ & Rate of enlargement of the fire front in the face $\mathrm{B}$ in the right direction \\
\hline$R_{3 B L}$ & m. $s^{-1}$ & Rate of enlargement of the fire front in the face $\mathrm{B}$ in the left direction \\
\hline$R_{3 B}$ & m. $s^{-1}$ & Average Rate of enlargement of the fire front in the face B \\
\hline$R^{\prime}$ & - & Non-dimensional rate of spread (NDROS) \\
\hline$x$ & $\mathrm{~m}$ & Distance measured along OX axis \\
\hline$y$ & $\mathrm{~m}$ & Distance measured along OY axis \\
\hline$z$ & $\mathrm{~m}$ & Distance measured along $\mathrm{OZ}$ axis \\
\hline a & $\mathrm{m}$ & Distance from the fire origin to the base of the hill \\
\hline $\mathrm{b}$ & $\mathrm{m}$ & Distance from the reference horizontal line on face $\mathrm{A}$ to the ridgeline \\
\hline $\mathrm{c}$ & $\mathrm{m}$ & Distance from the reference horizontal line on face $\mathrm{B}$ to the ridgeline \\
\hline $\mathrm{S}_{\mathrm{i}}$ & $\mathrm{m}$ & $\begin{array}{l}\text { Distance measured along reference direction i from the fire origin or from the } \\
\text { symmetry axis of the fire to its perimeter }\end{array}$ \\
\hline$k_{3}$ & - & Coefficient of relative rate of fire lateral enlargement in faces B and A \\
\hline$a_{3}$ & $\mathrm{~s}^{2} \cdot \mathrm{m}^{-2}$ & Empirical coefficient in equation (8) \\
\hline
\end{tabular}

\section{References}

Cabiddu, S., Congiu, F., Lara, G., Usai, L., and Becchia, A. (2010). "Analisi incendio boschivo. Rapporto di analisi e studio dell'incendio di Sa Costa, comune di Jerzu". Archivio CFVA Lanusei (OG), n. prot. 86, Pos. XI 2-5, 24 Settembre 2010... 
Ferreira, A.D., Lopes, A.M.G., Viegas, D.X., and Sousa, A.C.M. (1995). "Experimental and numerical simulation of flow around two-dimensional hills." Journal of Wind Engineering and Industrial Aerodynamics 54-55, 173-181.

McRae, R.H.D. (2004). "Breath of the dragon - observations of the January 2003 ACT Bushfires." Conference Bushfire 2004: Earth, Wind and Fire - Fusing the Elements. Adelaide: South Australian Department of Environment and Heritage: Adelaide, SA.

Sharples, J., McRae, R.H.D., and Wilkes, S.R. (2012). "Wind-terrain effects on the propagation of wildfires in rugged terrain: fire channelling." International Journal of Wildland Fire 21, 282-296.

Sharples, J.J., Viegas D.X., McRae R.H.D., Raposo J.R.N., and Farinha H.A.S. (2011). "Lateral bushfire propagation driven by the interaction of wind, terrain and fire." Proceedings of the 19th International Congress on Modelling and Simulation, 12-16.

Simpson, C., Sharples, J., Evans, J., and McCabe M. (2013). "Large eddy simulation of atypical wildland fire spread on leeward slopes." International Journal of Wildland Fire 22, 282-296

Viegas, D.X. (2006). "Parametric study of an eruptive fire behavior model." International Journal of Wildland Fire 15, 169-177.

Viegas, D.X. (2004). "On the existence of a steady state regime for slope and wind driven fires." International Journal of Wildland Fire 13, 101-117.

Viegas, D.X., and Neto, L.P. (1991). "Wall Shear-Stress as a Parameter to Correlate the Rate of Spread of a Wind Induced Forest Fire." International Journal of Wildland Fire 1, 177-188. 